Research article Open Access

\title{
The association of mammographic density with ductal carcinoma in situ of the breast: the Multiethnic Cohort
}

\author{
Jasmeet K Gill, Gertraud Maskarinec, lan Pagano and Laurence N Kolonel
}

\author{
Cancer Research Center of Hawaii, Honolulu, Hawaii, USA \\ Corresponding author: Jasmeet K Gill, jgill@crch.hawaii.edu
}

Received: 3 Mar 2006 Revisions requested: 6 Apr 2006 Revisions received: 22 May 2006 Accepted: 30 May 2006 Published: 23 Jun 2006

Breast Cancer Research 2006, 8:R30 (doi:10.1186/bcr1507)

This article is online at: http://breast-cancer-research.com/content/8/3/R30

(c) 2006 Gill et al.; licensee BioMed Central Ltd.

This is an open access article distributed under the terms of the Creative Commons Attribution License (http://creativecommons.org/licenses/by/2.0), which permits unrestricted use, distribution, and reproduction in any medium, provided the original work is properly cited.

\begin{abstract}
Introduction It is well established that women with high mammographic density are at greater risk for breast cancer than are women with low breast density. However, little research has been done on mammographic density and ductal carcinoma in situ (DCIS) of the breast, which is thought to be a precursor lesion to some invasive breast cancers.

Method We conducted a nested case-control study within the Multiethnic Cohort, and compared the mammographic densities of 482 patients with invasive breast cancer and 119 with breast DCIS cases versus those of 667 cancer-free control subjects. $A$ reader blinded to disease status performed computer-assisted density assessment. For women with more than one mammogram, mean density values were computed. Polytomous logistic regression models were used to compute adjusted odds ratios (ORs) and 95\% confidence intervals (Cls) for two measurements of mammographic density: percentage density and dense area.
\end{abstract}

Results Mammographic density was associated with invasive breast cancer and breast DCIS. For the highest category of percentage breast density $(\geq 50 \%)$ as compared with the lowest $(<10 \%)$, the OR was $3.58(95 \% \mathrm{Cl} 2.26-5.66)$ for invasive breast cancer and $2.86(1.38-5.94)$ for breast DCIS. Similarly, for the highest category of dense area $\left(\geq 45 \mathrm{~cm}^{2}\right)$ as compared with the lowest $\left(<15 \mathrm{~cm}^{2}\right)$, the OR was 2.92 (95\% Cl 2.014.25) for invasive breast cancer and 2.59 (1.39-4.82) for breast DCIS. Trend tests were significant for invasive breast cancer $(P$ for trend $<0.0001)$ and breast DCIS $(P$ for trend $<0.001)$ for both percentage density and dense area.

Conclusion The similar strength of association for mammographic density with breast DCIS and invasive breast cancer supports the hypothesis that both diseases may have a common etiology.

\section{Introduction}

As a result of increasing early detection efforts, breast carcinoma in situ (CIS) constitutes more than $20 \%$ of newly diagnosed breast cancer cases in the USA [1]. Although breast $\mathrm{CIS}$ shares a number of risk factors with invasive breast cancer, and ductal carcinoma in situ (DCIS) of the breast is considered to be a precursor to some invasive breast cancers [2], it is not clear to what extent breast CIS and invasive breast cancer have the same etiology. Several case-control studies have confirmed that mammographic density is associated with risk for breast cancer [3]; women with high breast density have a three-fold to six-fold greater risk for developing breast cancer than women with low breast density $[3,4]$. Most studies of mammographic density included only invasive breast cancer cases [5] or combined invasive and CIS cases [6-10]. One study investigating breast $\mathrm{CIS}$ observed that DCIS was more likely to occur in mammographically dense areas [11], and another study reported an increase in breast hyperplasia or atypia/CIS in women with greater than $50 \%$ breast density [12]. This analysis examines the association between mammographic density and risk for breast DCIS in comparison with invasive breast cancer and breast cancer-free control subjects.

\section{Materials and methods Study population}

The data for this analysis were collected using a nested casecontrol study within the Hawaii component of the Multiethnic Cohort, which was established between 1993 and 1996 [13]. As described in detail elsewhere [4], all female members 
Breast Cancer Research Vol 8 No 3 Gill et al.

Table 1

\begin{tabular}{|c|c|c|c|c|}
\hline Covariate & Invasive breast cancer & Breast DCIS & Controls & $P$ value ${ }^{a}$ \\
\hline Sample size & 482 & 119 & 667 & - \\
\hline Ethnicity (\%) & & & & $0.19^{b}$ \\
\hline Hawaiian & 14.3 & 8.4 & 24.3 & \\
\hline Japanese & 46.5 & 55.5 & 43.8 & \\
\hline Caucasian & 32.6 & 28.6 & 28.0 & \\
\hline Other & 6.6 & 7.6 & 3.9 & \\
\hline Age at diagnosis (years) & 63.5 & 62.9 & $\mathrm{~N} / \mathrm{A}$ & $0.50^{b}$ \\
\hline Age at recruitment (years) & 60.0 & 59.6 & 56.7 & $0.58^{b}$ \\
\hline Mean age at all mammograms (years) & 59.8 & 59.1 & 59.7 & 0.70 \\
\hline Body mass index $\left(\mathrm{kg} / \mathrm{m}^{2}\right)$ & 25.2 & 24.5 & 25.7 & 0.07 \\
\hline Time from first mammogram to diagnosis (years) & 6.2 & 6.7 & $\mathrm{~N} / \mathrm{A}$ & $0.17^{b}$ \\
\hline Family history of breast cancer (\%) & 16.8 & 16.8 & 12.0 & 0.05 \\
\hline Age at first birth (years) & 25.0 & 25.1 & 24.7 & 0.65 \\
\hline Age at menarche (years) & 13.1 & 12.9 & 13.1 & 0.47 \\
\hline Parous (\%) & 84.5 & 83.9 & 88.5 & 0.10 \\
\hline Number of children & 2.4 & 2.2 & 2.6 & 0.02 \\
\hline Postmenopausal (\%) & 86.3 & 89.9 & 77.7 & $<0.0001$ \\
\hline Ever HRT use (\%) & 67.2 & 73.9 & 69.3 & 0.01 \\
\hline Number of mammograms & $3.2^{\mathrm{c}}$ & $3.4^{\mathrm{c}}$ & $2.4^{\mathrm{c}}$ & $<0.0001$ \\
\hline Breast percent density ${ }^{d}$ & 36.5 & 38.2 & 29.4 & $<0.0001$ \\
\hline Breast dense aread $\left(\mathrm{cm}^{2}\right)$ & 36.7 & 34.9 & 28.7 & $<0.0001$ \\
\hline Total breast aread $\left(\mathrm{cm}^{2}\right)$ & 114.5 & 106.9 & 118.9 & 0.08 \\
\hline
\end{tabular}

Unless otherwise indicated, mean values are given. a $P$ ascertained from $t$ test or $\chi^{2}$ test, as appropriate. bCompares only invasive breast cancer and breast DCIS cases. All other comparisons are of invasive breast cancer cases, breast DCIS cases, and controls. cThe range for number of mammograms is 11,10 , and 7 for invasive breast cancer, breast DCIS, and controls, respectively. dAdjusted for age at recruitment. DCIS, ductal carcinoma in situ; HRT, hormone replacement therapy.

diagnosed with primary breast cancer between cohort entry and December 2000 were identified as potential cases $(n=$ 1,587). A similar number of randomly selected control subjects ( $n=1,584$ ) who were not known to have breast cancer were frequency matched to the distribution of ethnicity and 5year age groups of the cases. Cases and controls with a previous diagnosis of breast cancer, a history of breast augmentation or reduction, and no mammogram were excluded. Approximately $13 \%$ of breast cancer cases and $4 \%$ of controls were ineligible primarily because of death or pre-existent breast cancer. Of the 1,396 cases eligible to participate, $52.6 \%$ responded to the mailings and gave full consent. Of the 1,500 eligible controls, $48.7 \%$ responded to the mailings and gave full consent. After removing women who did not have suitable mammograms, the final sample consisted of 607 breast cancer cases and 667 control subjects. The original cohort and the nested case-control study were approved by the Committee on Human Studies at the University of Hawaii.
All participants provided informed consent to participate in both studies.

\section{Data collection}

Details of the study procedures were reported previously [4]. In brief, information on demographics, medical history, reproductive behavior, hormone replacement therapy (HRT) use, and body mass index (BMI) were collected with an extensive questionnaire at entry into the cohort during the period from 1993 to 1996 [13]. As part of the nested case-control study, a one-page Breast Health Questionnaire (BHQ) was completed to elicit information on menopausal status, previous breast surgery, mammography, and HRT medications [4].

\section{Mammograms}

The mammographic films were retrieved from clinics located throughout the State of Hawaii using the authorization forms signed by the study participants. The original cohort study had 
no records on mammography use except for one item in the baseline questionnaire. At that time, $90 \%$ of Caucasian and Japanese women and $75 \%$ of Native Hawaiian women reported previous mammography [14]. Only craniocaudal views were digitized using a Kodak LS 85 Film Digitizer with a pixel size of $260 \mu \mathrm{m}$. If available, mammograms for every second or third year were scanned with the goal being to cover as wide a time period as possible for each woman. For cases, only mammograms taken before treatment for breast cancer were selected. However, the image of the contralateral breast taken at the time of diagnosis was used for five cases. The scanned images for both breasts were assessed for densities using Cumulus108 software [15] by one reader (GM), who was blinded to case status and time sequence of the mammograms. After the reader determined a threshold for the edge of the breast and for the edge of the dense tissue [15], the computer calculated the total number of pixels in the digitized image that constituted the total area and the dense area and computed the ratio between the two values as percentage density. Because readings for the right and left breast were very similar (correlation coefficient $>0.90$ ), we averaged the values for both to obtain one measure of total breast area, dense area and percentage density.

A random sample of 410 mammograms was read in duplicate to assess the reliability of the mammographic readings. The intraclass correlation coefficients [16] were 0.96 (95\% confidence interval $(\mathrm{Cl})$ 0.95-0.97) for the size of dense area and 0.996 (95\% Cl 0.995-0.997) for the total breast area, resulting in an intraclass correlation coefficient for percentage density of 0.974 (95\% Cl $0.968-0.978)$.

\section{Statistical analysis}

To test for differences in covariate values across breast cancer cases and control subjects, we performed $t$ tests for continuous variables and $\chi^{2}$ tests for categorical variables. We used unconditional polytomous logistic regression modeling with the SAS software [17] to compute odds ratios (ORs) and 95\% Cls for the risks for DCIS and invasive cancer associated with breast density [18]. All $P$ values reported are two sided. Breast cancer cases were divided into CIS and invasive based on information provided by the state-wide Hawaii Tumor Registry, a member of the National Cancer Institute's Surveillance, Epidemiology and End Results program. Of the 125 breast CIS cases, 119 were classified as having DCIS.

We chose two measures of mammographic breast density as our exposure variables: size of the dense area and percentage density. Percentage density was grouped into four commonly used categories: $<10 \%, 10-24.9 \%, 25-49.9 \%$, and $\geq 50 \%$. The size of the dense areas was classified as follows: $<15$ $\mathrm{cm}^{2}, 15-29.9 \mathrm{~cm}^{2}, 30.0-44.9 \mathrm{~cm}^{2}$, and $\geq 45 \mathrm{~cm}^{2}$. Study participants were grouped into four categories: Japanese, Caucasians, native Hawaiians and others (mostly Filipinos). To maximize the number of participants per group, women of mixed ancestry - regardless of admixture - were assigned to one ethnic category according to the following priority ranking: native Hawaiian, Japanese, Caucasian, and, finally, other [13]. We created an HRT variable using the responses from the questionnaire at cohort entry and from the $\mathrm{BHQ}$ at enrollment into the breast density study. A comparison of the HRT information from the two questionnaires exhibited good agreement for overlapping years when both questionnaires reported HRT use. If a woman indicated that she had used HRT at any time but the write-in field in the $\mathrm{BHO}$ was empty, we assigned the type of HRT from the cohort questionnaire completed at baseline. For the women with missing HRT type information (5.4\%), we imputed the type based on hysterectomy status: estrogen only for women with a hysterectomy and combined therapy otherwise.

All models were adjusted for the following covariates that are known to be associated with breast cancer and mammographic density: mean age of all mammograms (continuous), ethnicity, BMI $\left(<22.5,22.5\right.$ to $<25,25$ to $<30$, or $\left.\geq 30 \mathrm{~kg} / \mathrm{m}^{2}\right)$, parity $(0-1,2-3$, or $\geq 4)$, age at menarche $(<13,13-14$, or $\geq 15$ years), age at first live birth $(<21,21-30,>30$ years, or no children), menopausal status (pre- or postmenopausal), family history of breast cancer (breast cancer in a first-degree relative or no history), and HRT use (never, estrogen only, or estrogen + progestin). Tests for trend were performed by fitting a variable representing ordinal categories (described above) of percentage density or dense area.

We were also interested in comparing how well percentage breast density and size of dense area predicted invasive breast cancer and breast DCIS. We performed unconditional binary logistic regression and examined the area under the receiver operating characteristic (ROC) curve, which is a method used in sensitivity-specificity analyses. The ROC curve assesses the ability of the model to distinguish between two groups (for example, diseased and disease free). If the model is able to separate the two groups perfectly, then the area under the ROC curve is equal to 1 ; if the model performs no better than chance, then the area will be 0.5 .

\section{Results}

Of all breast cancer cases, 119 (19.8\%) were breast DCIS (Table 1). Japanese women had a greater proportion of breast DCIS than invasive breast cancer, and native Hawaiian women had almost twice the proportion of invasive cases compared with $\mathrm{DCIS}$ cases $(P=0.19)$. The mean age at diagnosis was similar for breast DCIS and invasive cases $(P=0.50)$. However, the breast DCIS cases had a greater proportion of postmenopausal women $(89.9 \%$ versus $86.3 \%$ and $77.7 \%$ (for DCIS, invasive cases, and controls, respectively)) and had fewer children (2.2 versus 2.4 and 2.6 (for DCIS, invasive cases and controls, respectively)). Women with invasive breast cancer or breast DCIS had more mammograms than did controls $(P<0.0001)$. However, mean unadjusted age at 
Table 2

Mammographic breast density and risk estimates for breast DCIS and invasive breast cancer

\begin{tabular}{|c|c|c|c|c|c|c|}
\hline Exposure variable & Invasive breast cancer $(n)$ & Breast DCIS $(n)$ & Controls $(n)$ & Invasive versus controls & DCIS versus controls & DCIS versus invasive \\
\hline \multicolumn{7}{|c|}{ Mean percentage density (\%) } \\
\hline$<10$ & 63 & 18 & 158 & 1 (reference) & 1 (reference) & 1 (reference) \\
\hline $10-24.9$ & 110 & 23 & 170 & $1.81(1.21-2.70)$ & $1.15(0.57-2.30)$ & $0.65(0.31-1.35)$ \\
\hline $25-49.9$ & 174 & 34 & 212 & $2.53(1.69-3.78)$ & $1.29(0.64-2.59)$ & $0.56(0.27-1.17)$ \\
\hline$\geq 50$ & 135 & 44 & 127 & $3.58(2.26-5.66)$ & $2.86(1.38-5.94)$ & $0.89(0.41-1.91)$ \\
\hline$P$ value for trend & & & & $<0.0001$ & 0.0010 & \\
\hline \multicolumn{7}{|c|}{ Mean breast dense area $\left(\mathrm{cm}^{2}\right)$} \\
\hline$<15$ & 95 & 26 & 209 & 1 (reference) & 1 (reference) & 1 (reference) \\
\hline $15-29.9$ & 136 & 29 & 200 & $1.58(1.12-2.23)$ & $1.05(0.58-1.92)$ & $0.75(0.40-1.40)$ \\
\hline $30-44.9$ & 109 & 28 & 133 & $1.93(1.32-2.81)$ & $1.70(0.90-3.22)$ & $0.92(0.48-1.76)$ \\
\hline$\geq 45$ & 142 & 36 & 125 & $2.92(2.01-4.25)$ & $2.59(1.39-4.82)$ & $0.99(0.53-1.86)$ \\
\hline$P$ value for trend & & & & $<0.0001$ & 0.0026 & \\
\hline
\end{tabular}

Values are expressed as odds ratios (95\% confidence intervals), which were estimated using polytomous logistic regression and adjusted for ethnicity, mean age of all mammograms, body mass index, age at first live birth, number of children, age at menarche, menopausal status, use of hormone replacement therapy, and family history of breast cancer. DCIS, ductal carcinoma in situ.

first mammogram and last mammogram were not different across breast DCIS cases, invasive breast cancer cases, and controls $(P=0.32$ and $P=0.66$, respectively; results not shown). Although invasive breast cancer cases had a greater age-adjusted mean dense breast area than did breast DCIS cases (36.7 $\mathrm{cm}^{2}$ and $34.9 \mathrm{~cm}^{2}$, respectively), the breast DCIS cases had higher percentage breast densities $(38.2 \%$ and $36.5 \%$, respectively) than did the invasive breast cancer cases because of their smaller mean total breast area.

Both percentage density and the size of the dense area were associated with breast DCIS and invasive breast cancer in our study (Table 2). For each cancer, trend tests were highly significant. Women with at least $50 \%$ percentage density had a 3.5-fold greater risk for invasive breast cancer than women with less than 10\% density (OR 3.58, 95\% Cl 2.26-5.66) when compared with controls. The risk for DCIS was almost threefold greater in women with $50 \%$ or more percentage density than in women with less than $10 \%$ density (OR 2.86, 95\% Cl 1.38-5.94). For breast DCIS, the $95 \%$ Cls for the second and third categories of density included the null value. The comparison of breast DCIS with invasive breast cancer indicated a lower, although not statistically significant, risk for breast DCIS than for invasive cancer given the same level of percentage density. The risk estimates for the size of dense area in the breast were not as strong as they were for percentage breast density. For women with more than $45 \mathrm{~cm}^{2}$ of dense breast area, the ORs of invasive breast cancer and breast DCIS were 2.92 (95\% Cl 2.01-4.25) and $2.86(95 \%$ Cl 1.57-5.20), respectively, compared with controls. The comparison of breast DCIS versus invasive breast cancer cases showed little difference.
Because of sample size limitations, we were only able to analyze mammographic density and risk for breast DCIS by ethnicity for Japanese and Caucasian women (results not shown). Both ethnic groups exhibited similar trends; risk for breast DCIS increased with increasing percentage density and dense area. However, the $\mathrm{Cls}$ were wide and, except for the highest category of percentage density and dense area in Caucasian women, all intervals included 1.

The area under the ROC curve was similar for percentage density and dense area. For the adjusted invasive breast cancer model, both values were 0.74 , whereas for the adjusted breast DCIS model the areas under the ROC curve were 0.67. When modeled without adjustment for covariates, the area under the ROC curve for invasive breast cancer was 0.59 for both percentage density and dense area. A similar unadjusted model for DCIS yielded values of 0.59 for dense area and 0.61 for percentage density.

\section{Discussion}

Our analyses revealed that mammographic breast density, as measured by percentage density and the size of dense area, is associated with breast DCIS as well as invasive breast cancer. The association was slightly weaker for breast DCIS than for invasive breast cancer. Comparisons of areas under the ROC curve indicated that breast density and dense area performed equally well in distinguishing breast DCIS and invasive breast cancer cases from controls. The ORs for breast DCIS in the present study were not as large as those reported in a study of a cohort of Canadian women [12], which estimated relative risks between 7 and 12 for detecting atypia/CIS in biopsy specimens from women with more than $50 \%$ density. However, the cell sizes within the strata of density were small in that 
study and cases were selected from a group of women with biopsies. A British case-control study [19] found much lower risks for breast CIS, and the estimates were similar in strength to those for invasive breast cancer. Women with Wolfe parenchymal patterns P2 or DY had $70 \%$ greater risk $(95 \% \mathrm{Cl} 1.1-$ 2.6) of screening detected in situ breast cancer compared with controls and a $30 \%$ greater risk $(95 \% \mathrm{Cl} 1.2-1.8)$ of screening detected invasive breast cancer compared with controls.

Other studies of breast DCIS support the idea that there is a relation between in situ lesions and mammographic density. An investigation of 28 mammograms confirmed that breast DCIS occurs to a greater extent in areas of the breast that exhibit high mammographic density [11]. The relative risk for a second breast cancer was found to be three times higher among women with primary DCIS who had mammographic densities of $75 \%$ and greater compared with women with less than $25 \%$ density [20].

Although it is known that some breast DCIS lesions will develop into invasive breast cancers [21], and that DCIS is often found near invasive breast cancer lesions [22], it remains problematic to distinguish DCIS lesions that may progress to invasive breast cancer from those that may not. Given the growing number of breast CIS cases with increasing mammography screening [1], this question has important implications when decisions must be made regarding the aggressiveness of treatment [23]. A comparison of risk factors for CIS (ductal and/or lobular) and invasive breast cancer found mixed results. Established invasive breast cancer risk factors shown to be consistently associated with breast CIS include family history of breast cancer [24-30], low BMI among premenopausal women [24,29,30], and nulliparity $[24,28,30,31]$. However, other invasive breast cancer risk factors such as early age at menarche, late age at menopause, increased endogenous estrogen levels, and alcohol intake were associated with breast CIS in some studies $[26,27,29,32]$, but not in others [24-27,30,33].

Our study and other reports mentioned above indicate that mammographic density is associated with breast $\mathrm{CIS}$ and with invasive breast cancer. However, because some studies describe differential effects for some risk factors, more research needs to be done. Studies with larger samples of breast CIS must be performed to assess whether factors such as postmenopausal obesity, growth factors (insulin-like growth factor-I), exogenous hormones, and cell proliferation biomarkers can help in elucidating the association between breast density, breast $\mathrm{ClS}$, and progression to invasive breast cancer. New molecular techniques may have the ability to identify factors that are responsible for the progression from DCIS to invasive cancer [2].
A limitation of the present study is the lack of data on the frequency of mammography use. Although this population has high screening rates [14], we cannot rule out bias toward the null in estimates of DCIS risk because of the possibility of undetected breast DCIS among controls. We also had relatively low participation rates, although a comparison of participating and eligible women revealed that they had very similar characteristics [4]. Our assessments of HRT and BMI are limited because we had to rely on self-report, and assumed that their values remained constant between the time they were reported and when the study was completed, but an examination of BMl from a follow-up questionnaire five years after cohort entry showed that the mean BMl changes by only 0.50 $\mathrm{kg} / \mathrm{m}^{2}$ during that time. Therefore, differences in BMl are unlikely to change the results materially. The use of BMI in categories is unlikely to have confounded our results because analyses with continuous values of BMl gave nearly identical results. We had limited power to estimate the risk for DCIS; there were nearly four times as many invasive breast cancer cases as breast DCIS cases. Nevertheless, the cohort design, the multiple mammograms, and the frequent mammography use in this population must be considered strengths of this project. The high rate of mammography participation decreases the probability that a large number of cancers were missed in this population.

\section{Conclusion}

In the present study similar patterns of association for mammographic density with DCIS and invasive breast cancers add to the growing body of evidence that certain breast CIS and invasive breast cancers may share etiologic factors. At the same time, it appears likely that factors that have not yet been identified may influence the effects of breast density and other known breast cancer risk factors in the progression of breast $\mathrm{CIS}$ to invasive breast cancer.

\section{Competing interests}

The authors declare that they have no competing interests.

\section{Authors' contributions}

JG carried out the main statistical analysis, created variables used in this analysis, and drafted the manuscript. GM conceived of the nested case-control study, performed the mammographic density assessment, and helped with the draft and revisions of the manuscript. IP created a data set and variables used in analysis, assisted in writing of SAS programs, and advised on statistical analysis techniques. LK conceived of the Multiethnic Cohort and helped in revision of the manuscript. All authors read and approved the final manuscript.

\section{Acknowledgements}

The case-control study was funded by a grant from the National Cancer Institute (R01 CA 85265). The Multiethnic Cohort Study has been supported by USPHS (National Cancer Insitute) grant R37 CA 54281. Dr Gill was supported by R25 CA 90956 . We are very grateful to Jihae Noh for her outstanding work in mammogram retrieval and scanning, to 
Andrew Williams for the excellent database, and to Maj Earle for providing information from the Multiethnic Cohort Study.

\section{References}

1. American Cancer Society SR2: Cancer Facts and Figures 2005 Atlanta, GA: American Cancer Society, Inc.; 2005.

2. Bernstein L: The epidemiology of breast carcinoma in situ. In Ductal Carcinoma In Situ of the Breast 2nd edition. Edited by: Silverstein MJ, Recht A, Lagios MD. Philadelphia: Lippincott, Williams and Wilkins; 2002.

3. Boyd NF, Rommens JM, Vogt K, Lee V, Hopper JL, Yaffe MJ, Paterson $\mathrm{AD}$ : Mammographic breast density as an intermediate phenotype for breast cancer. Lancet Oncol 2005, 6:798-808.

4. Maskarinec G, Pagano I, Lurie G, Wilkens LR, Kolonel LN: Mammographic density and breast cancer risk: the Multiethnic Cohort. Am J Epidemiol 2005, 162:743-752.

5. Ursin G, Ma H, Wu AH, Bernstein L, Salane M, Parisky YR, Astrahan M, Siozon CC, Pike MC: Mammographic density and breast cancer in three ethnic groups. Cancer Epidemiol Biomarkers Prev 2003, 12:332-338.

6. Torres-Mejia G, De Stavola B, Allen DS, Perez-Gavilan JJ, Ferreira JM, Fentiman IS, Dos Santos Silva I: Mammographic features and subsequent risk of breast cancer: a comparison of qualitative and quantitative evaluations in the Guernsey prospective studies. Cancer Epidemiol Biomarkers Prev 2005, 14:1052-1059.

7. Maskarinec G, Meng L: A case-control study of mammographic densities in Hawaii. Breast Cancer Res Treat 2000 63:153-161.

8. Byrne C, Schairer C, Wolfe J, Parekh N, Salane M, Brinton LA, Hoover R, Haile R: Mammographic features and breast cancer risk: effects with time, age, and menopause status. J Natl Cancer Inst 1995, 87:1622-1629.

9. Boyd NF, Byng JW, Jong RA, Fishell EK, Little LE, Miller AB, Lockwood GA, Tritchler DL, Yaffe MJ: Quantitative classification of mammographic densities and breast cancer risk: results from the Canadian National Breast Screening Study. J Natl Cancer Inst 1995, 87:670-675.

10. Saftlas AF, Hoover RN, Brinton LA, Szklo M, Olson DR, Salane M, Wolfe JN: Mammographic densities and risk of breast cancer. Cancer 1991, 67:2833-2838.

11. Ursin G, Hovanessian-Larsen L, Parisky YR, Pike MC, Wu AH: Greatly increased occurrence of breast cancers in areas of mammographically dense tissue. Breast Cancer Res 2005, 7:R605-R608.

12. Boyd NF, Jensen HM, Cooke G, Lee Han H: Relationship between mammographic and histological risk factors for breast cancer. J Nat/ Cancer Inst 1992, 15:1170-1179.

13. Kolonel LN, Henderson BE, Hankin JH, Nomura AMY, Wilkens LR, Pike MC, Stram DO, Monroe KR, Earle ME, Nagamine FS: A Multiethnic Cohort in Hawaii and Los Angeles: baseline characteristics. Am J Epidemio/ 2000, 151:346-357.

14. Hawaii State Department of Health: Hawaii Behavioral Risk Factor Surveillance Report 1994-2000 Honolulu: State of Hawaii; 2002

15. Byng JW, Boyd NF, Fishell E, Jong RA, Yaffe MJ: The quantitative analysis of mammographic densities. Phys Med Biol 1994, 39:1629-1638.

16. Shrout $P$, Fleiss J: Intraclass correlations: uses in assessing rater reliability. Psychol Bull 1979, 86:420-428.

17. SAS Institute Inc: SAS OnlineDoc 9.1.2 Cary, NC: SAS Institute Inc; 2004

18. Hosmer DW, Lemeshow S: Applied Logistic Regression 2nd edition. New York: John Wiley \& SOns Inc; 2000

19. Sala E, Solomon L, Warren R, McCann J, Duffy S, Luben R, Day N: Size, node status and grade of breast tumours: association with mammographic parenchymal patterns. Eur Radio/ 2000, 10:157-161.

20. Habel LA, Dignam JJ, Land SR, Salane M, Capra AM, Julian TB: Mammographic density and breast cancer after ductal carcinoma in situ. J Nat/ Cancer Inst 2004, 96:1467-1472.

21. Page DL, Dupont WD, Rogers LW, Jensen RA, Schuyler PA: Continued local recurrence of carcinoma 15-25 years after a diagnosis of low grade ductal carcinoma in situ of the breast treated only by biopsy. Cancer 1995, 76:1197-1200.
22. Ernster VL, Barclay J, Kerlikowske K, Grady D, Henderson IC: Incidence of and treatment for ductal carcinoma in situ of the breast. JAMA 1996, 275:913-918.

23. Leonard GD, Swain SM: Ductal carcinoma in situ, complexities and challenges. J Natl Cancer Inst 2004, 96:906-920.

24. Kerlikowske K, Barclay J, Grady D, Sickles EA, Ernster V: Comparison of risk factors for ductal carcinoma in situ and invasive breast cancer. J Natl Cancer Inst 1997, 89:76-82.

25. Gapstur SM, Morrow M, Sellers TA: Hormone replacement therapy and risk of breast cancer with a favorable histology: results of the lowa Women's Health Study. JAMA 1999, 281:2091-2097.

26. Trentham-Dietz A, Newcomb PA, Storer BE, Remington PL: Risk factors for carcinoma in situ of the breast. Cancer Epidemiol Biomarkers Prev 2000, 9:697-703.

27. Claus EB, Stowe M, Carter D: Breast carcinoma in situ: risk factors and screening patterns. J Natl Cancer Inst 2001, 93:1811-1817.

28. Brinton LA, Hoover R, Fraumeni JF Jr: Epidemiology of minimal breast cancer. JAMA 1983, 249:483-487.

29. Longnecker MP, Bernstein L, Paganini-Hill A, Enger SM, Ross RK: Risk factors for in situ breast cancer. Cancer Epidemiol Biomarkers Prev 1996, 5:961-965.

30. Weiss HA, Brinton LA, Brogan D, Coates RJ, Gammon MD, Malone KE, Schoenberg JB, Swanson CA: Epidemiology of in situ and invasive breast cancer in women aged under $45 . \mathrm{Br} J$ Cancer 1996, 73:1298-1305.

31. Lambe M, Hsieh CC, Tsaih SW, Ekbom A, Trichopoulos D, Adami HO: Parity, age at first birth and the risk of carcinoma in situ of the breast Int J Cancer 1998, 77:330-332.

32. Missmer SA, Eliassen AH, Barbieri RL, Hankinson SE: Endogenous estrogen, androgen, and progesterone concentrations and breast cancer risk among postmenopausal women. J Nat/ Cancer Inst 2004, 96:1856-1865.

33. Zeleniuch-Jacquotte A, Gu Y, Shore RE, Koenig KL, Arslan AA Kato I, Rinaldi S, Kaaks R, Toniolo P: Postmenopausal levels of sex hormones and risk of breast carcinoma in situ: results of a prospective study. Int J Cancer 2005, 114:323-327. 